\title{
Development of Low-Yield Stress Co-Cr-W-Ni Alloy by Adding 6 Mass Pct Mn for Balloon-Expandable Stents
}

\author{
SOH YANAGIHARA, KOSUKE UEKI, KYOSUKE UEDA, MASAAKI NAKAI, \\ TAKAYOSHI NAKANO, and TAKAYUKI NARUSHIMA
}

\begin{abstract}
This is the first report presenting the development of a $\mathrm{Co}-\mathrm{Cr}-\mathrm{W}-\mathrm{Ni}-\mathrm{Mn}$ alloy by adding 6 mass pet $\mathrm{Mn}$ to ASTM F90 Co-20Cr-15W-10Ni (CCWN, mass pet) alloy for use as balloon-expandable stents with an excellent balance of mechanical properties and corrosion resistance. The effects of $\mathrm{Mn}$ addition on the microstructures as well as the mechanical and corrosion properties were investigated after hot forging, solution treatment, swaging, and static recrystallization. The Mn-added alloy with a grain size of $\sim 20 \mu \mathrm{m}$ (recrystallization condition: $1523 \mathrm{~K}, 150$ seconds) exhibited an ultimate tensile strength of $1131 \mathrm{MPa}, 0.2$ pct proof stress of $535 \mathrm{MPa}$, and plastic elongation of 66 pct. Additionally, it exhibited higher ductility and lower yield stress while maintaining high strength compared to the ASTM F90 CCWN alloy. The formation of intersecting stacking faults was suppressed by increasing the stacking fault energy (SFE) with Mn addition, resulting in a lower yield stress. The low-yield stress is effective in suppressing stent recoil. In addition, strain-induced martensitic transformation during plastic deformation was suppressed by increasing the SFE, thereby improving the ductility. The Mn-added alloys also exhibited good corrosion resistance, similar to the ASTM F90 CCWN alloy. Mn-added $\mathrm{Co}-\mathrm{Cr}-\mathrm{W}-\mathrm{Ni}$ alloys are suitable for use as balloon-expandable stents.
\end{abstract}

https://doi.org/10.1007/s11661-021-06374-7

(C) The Author(s) 2021

\section{INTRODUCTION}

Minimally invasive medical treatment approaches are in high demand for stent surgery to minimize operative trauma in patients. The Co-20Cr-15W-10Ni (CCWN, mass pct, L605) alloy registered as ASTM F90 has been used as a balloon-expandable stent because of its excellent mechanical and corrosion properties. ${ }^{[1-4]}$ Additionally, it is essential to reduce the diameter of the stent. This requires both high strength and high ductility of CCWN alloys. Furthermore, the yield stress must be kept to a minimum to enable easy expansion during balloon dilation and

SOH YANAGIHARA, KYOSUKE UEDA, and TAKAYUKI NARUSHIMA are with the Department of Materials Processing, Graduate School of Engineering, Tohoku University, 6-6-02, AzaAoba, Aramaki, Aoba-ku, Sendai 980-8579, Japan. Contact e-mail: soh.yanagihara@gmail.com KOSUKE UEKI and MASAAKI NAKAI are with the Department of Mechanical Engineering, Faculty of Science and Engineering, Kindai University, 3-4-1, Kowakae, Higashiosaka 577-8502, Japan. TAKAYOSHI NAKANO is with the Division of Materials and Manufacturing Science, Graduate School of Engineering, Osaka University, 2-1, Yamada-Oka, Suita, Osaka 565-0871 Japan.

Manuscript submitted April 16, 2021; accepted June 25, 2021.

Article published online July 7, 2021 suppress stent recoil. ${ }^{[1,5,6]}$ Therefore, there are two possible development guidelines for the next generation of balloon-expandable stents: increasing the strength and ductility while maintaining a certain level of yield stress ("high-strength type") and lowering the yield stress while maintaining a certain level of strength and ductility ("low-yield stress type").

Previous studies have focused on the development of "high-strength types." Because microstructural evolution such as grain size change, ${ }^{[2,7,8]}$ precipitate formation, ${ }^{[5,9-13]}$ and phase transformation ${ }^{[14-16]}$ occur in CCWN alloys during thermomechanical treatment, it is essential to understand the role of microstructural evolution in improving the mechanical properties of the alloys through microstructural control. ${ }^{[15,17-24]}$ Ueki et al. ${ }^{[17]}$ designed alloys that can achieve high ductility by low-temperature heat treatment (LTHT) at $873 \mathrm{~K}$ in addition to high strength by grain refinement via static recrystallization. Improvement of ductility by LTHT has also been reported in biomedical $\mathrm{Co}-27 \mathrm{Cr}-6 \mathrm{Mo}$ alloys (mass pct). ${ }^{[25]} \mathrm{Li}$ et al. ${ }^{[19-23]}$ achieved high strength in CCWN alloys through the formation of a bimodal grain structure. Moreover, they reported that a bimodal grain structure can be formed by performing cold rolling and static recrystallization five times, resulting in high strength and high ductility. ${ }^{[2]}$ However, these studies 
reported the ultimate tensile strength as well as an increase in the yield stress; thus, increasing the strengthening. Therefore, in this study, we focused on developing a new alloy based on CCWN alloy to produce a "low-yield stress type" stent material. ${ }^{[26]}$

Twinning induced plasticity (TWIP) steels contain Mn, which is an austenite stabilizing element in Fe, resulting in a stacking fault energy (SFE) at room temperature of approximately 20 to $40 \mathrm{~mJ} \mathrm{~m}{ }^{-2}$. ${ }^{[27]}$ Therefore, in the fcc alloy, it is presumed that the composition should be controlled such that the SFE is in the range of 20 to $40 \mathrm{~mJ}$ $\mathrm{m}^{-2}$ to exhibit TWIP-like plastic deformation behavior. The SFE of ASTM F90 Co-Cr-W-Ni (Base) alloy at room temperature is approximately $25 \mathrm{~mJ} \mathrm{~m}^{-2}$. ${ }^{[17]}$ To achieve low-yield stress and high strength (excellent work-hardening performance) such as TWIP in the Co-based alloy, it is necessary to increase SFE. Therefore, we attempted to add Mn as a $\gamma$-stabilizing element in order to increase the SFE. In our previous study, an alloy with 8 mass pet Mn added to the ASTM F90 CCWN alloy (average grain size: $129 \mu \mathrm{m}$ ) achieved high ductility (75 pct of plastic elongation) and exhibited an increased work hardening rate during plastic deformation. ${ }^{[26}$ Furthermore, the 8 mass pct Mn-added CCWN alloy showed a lower yield stress than that of the ASTM F90 composition alloy with an average grain size of $207 \mu \mathrm{m} .{ }^{[26]}$ Mn was chosen as the alloying element for the CCWN alloy because it not only acts as a $\gamma$-stabilizing element, ${ }^{[2-30]}$ but also increases twinnability ${ }^{[29]}$ and suppresses precipitate formation ${ }^{[31]}$ in Co-based alloys. In addition, $\mathrm{Mn}$ is also an essential trace element for the human body and is suitable as an alloying element for biomedical metallic materials. However, the addition of 8 mass pct Mn reduces not only the yield stress, but also the ultimate tensile strength of the ASTM F90 composition alloy ${ }^{[26]}$; hence, it is necessary to optimize the alloy composition. In addition, considering that the grain size in current balloon-expandable stents is approximately $30 \mu \mathrm{m}$ or smaller, ${ }^{[5]}$ it is important to clarify the grain size effect on the mechanical properties of the Mn-added CCWN alloy in the range of around 20 to $40 \mu \mathrm{m}$.

In a preliminary study, alloys with 4 and 6 mass pet Mn added to ASTM F90 CCWN alloy were fabricated and evaluated. No significant differences were observed between the ASTM F90 CCWN alloy and the 4 mass pct Mn-added CCWN alloy in terms of yield stress, ultimate tensile strength, and ductility. Therefore, we decided to focus on the 6 mass pet Mn added alloy.

In this study, we developed a $\mathrm{Co}-\mathrm{Cr}-\mathrm{W}-\mathrm{Ni}-\mathrm{Mn}$ alloy by adding 6 mass pet Mn to ASTM F90 CCWN alloy to obtain "low-yield stress type" stent materials. We then investigated the effects of adding Mn on the alloy microstructure and the mechanical and corrosion properties.

\section{EXPERIMENTAL}

\section{A. Alloy Preparation and Thermomechanical Treatment}

The raw materials used were $\mathrm{Co}-20.12 \mathrm{Cr}-14.94 \mathrm{~W}-$ $9.77 \mathrm{Ni}-1.86 \mathrm{Fe}-1.58 \mathrm{Mn}-0.079 \mathrm{C}-0.033 \mathrm{~N}$ (mass pct, Carpenter Technology Corporation, Lot 1) alloy forged bar and $\mathrm{Co}-20.43 \mathrm{Cr}-15.14 \mathrm{~W}-10.19 \mathrm{Ni}-2.61 \mathrm{Fe}-1.81 \mathrm{Mn}-0.084 \mathrm{C}$ (mass pct, VDM Metals, DEU, Lot 2) alloy forged bar. Both were based on ASTM F90 standard chemical composition. These alloys are referred to as Base alloys. The Base alloy (Lot 1 or Lot 2) and pure Mn were melted in a high-frequency induction melting furnace and cast into $\phi 32 \mathrm{~mm}$ molds to produce $\phi 32$ $\times 200 \mathrm{~mm}$ alloy bars (as-cast alloys) with the composition shown in Table I. The melted alloy is referred to as a $6 \mathrm{Mn}$ alloy. Because the compositions of 6Mn alloys melted from Lot 1 and Lot 2 have no significant difference, hereafter we refer to them as $6 \mathrm{Mn}$ alloys.

Figure 1 shows a schematic of the thermomechanical treatment process used in this study. The as-cast alloys were hot forged to a diameter of $\phi 18 \mathrm{~mm}$ at $1473 \mathrm{~K}$ to homogenize the casting structure (as-forged alloys). The as-forged alloys were solution-treated at $1523 \mathrm{~K}$ for $7.2 \mathrm{ks}$ followed by Ar gas quenching at 3 bar (ST alloys). The ST alloys were subjected to swaging at approximately 55 pct cross-sectional area reduction (swaged alloys). Bars of $\phi 6.5 \times 45 \mathrm{~mm}$ were cut from the swaged alloys. These specimens were enclosed in silica ampoules with Ar gas and subjected to recrystallization at 1423 to $1523 \mathrm{~K}$ for 150 to 3600 seconds. After recrystallization, the silica ampoule was immediately crushed in ice water, and the specimen was water-quenched.

Similarly, the recrystallized Base alloys were prepared by swaging (52 pct) and recrystallization at $1473 \mathrm{~K}$ for 100,300 , and 3600 seconds to compare the mechanical properties exhibited by the alloys in both methods.

Table I. Chemical Compositions of the Alloys Fabricated in This Study (Mass Percent)

\begin{tabular}{lllllll}
\hline Abbreviation & & Co & Cr & W & Ni & Mn \\
\hline 6Mn & Lot 1 & bal. & 19.16 & 14.15 & 9.40 & 6.01 \\
& Lot 2 & bal. & 19.40 & 14.64 & 9.90 & 6.02 \\
Base & Lot 1 & bal. & 20.12 & 14.94 & 9.77 & 1.58 \\
& Lot 2 & bal. & 20.43 & 15.14 & 10.19 & 1.81 \\
\hline
\end{tabular}

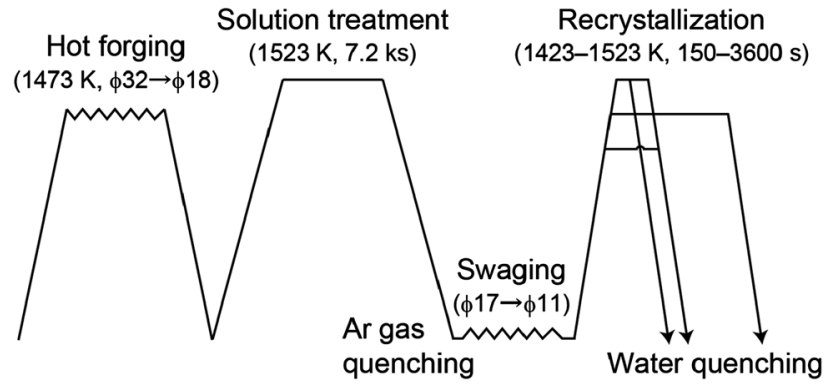

Fig. 1-Thermomechanical treatment process using hot forging, solution treatment, swaging, and recrystallization. 


\section{B. Microstructure Observation and Analysis}

Microstructural characterization of the recrystallized alloys was performed using electron backscattering diffraction (EBSD, JSM-7800F, JEOL Ltd., JPN) and transmission electron microscopy (TEM, JEM-2100, JEOL Ltd., JPN). The specimens for EBSD analysis were mechanically polished, buffed with $0.3 \mu \mathrm{m}$ alumina powder, and then vibrationally polished.

Specimens approximately $100 \mu \mathrm{m}$ thick were prepared by jet electropolishing for TEM observation. A volume of 10 pet $\mathrm{H}_{2} \mathrm{SO}_{4}-90$ pet $\mathrm{CH}_{3} \mathrm{OH}$ solution was used as the electrolyte. The specimens were punched with holes by ion milling, and the areas near the holes were selected as the observation sites.

\section{Tensile Testing}

Tensile specimens with a gauge section of $\phi 3 \times 10 \mathrm{~mm}$ were machined from the recrystallized bars. Tensile tests were conducted to fracture the specimens using a mechanical testing machine (RTF-1325, A\&D Company Ltd., JPN) with a nominal strain rate of $1.67 \times 10^{-4} \mathrm{~s}^{-1}$ at $298 \mathrm{~K}$. Plastic elongation was determined from the fractured specimens butted together.

For some of the recrystallized alloys, tensile tests were stopped at predetermined strain levels to prepare specimens with true strain levels of 0.15 and 0.4 , followed by EBSD analyses.

\section{Anodic Polarization Testing}

The corrosion properties of the alloys were evaluated using anodic polarization tests. Test electrodes were prepared with a size of $8 \times 12.5 \times 3 \mathrm{~mm}$, such that the area of the exposed part of the electrodes was approximately $1 \mathrm{~cm}^{2}$. The conductive wire was fixed to the backside of the specimen and covered with epoxy resin. Thereafter, the specimen surface was polished to a mirror finish.

Anodic polarization tests were conducted using a potentiostat and electrochemical measurement software (HZ-5000, Hokuto Denko Co., JPN) with a Pt mesh as the counter electrode and a silver/silver chloride electrode (SSE) as the reference electrode. All experiments were performed at $310 \mathrm{~K}$. Hanks' balanced salt solution ( $\mathrm{pH}$ 7.4) was used as the test solution to simulate the human body environment. Before starting the anodic polarization test, the potential after immersing the specimens in the salt solution for 10 minutes was measured and used as the open circuit potential (OCP). The amount of change in potential per 10 seconds after a 10-minute OCP measurement was less than $5 \mu \mathrm{V}$. The detailed procedure for anodic polarization testing was reported in a previous study. ${ }^{[15]}$

\section{RESULTS}

\section{A. Microstructure of Recrystallized Alloys}

Figure 2 shows the EBSD inverse pole figure (IPF) maps of $6 \mathrm{Mn}$ and Base alloys recrystallized at $1423 \mathrm{~K}$ to
$1523 \mathrm{~K}$ for 150 to 3600 seconds. Microstructures containing a large number of annealing twins were formed in both $6 \mathrm{Mn}$ and Base alloys under recrystallization conditions. The grains become coarser as the recrystallization temperature and holding time increase. The average grain size was calculated to be in the range of 6 to $147 \mu \mathrm{m}$ from the IPF map. Henceforth, recrystallized alloys will be referred to by their grain sizes (d), for example "6Mn-d41 alloy." The recrystallization conditions, corresponding grain sizes, and alloy abbreviations are listed in Table II. Figure 3 shows the phase and kernel average misorientation (KAM) maps of the $6 \mathrm{Mn}-\mathrm{d} 5$ alloy with the smallest grain size among the alloys used in this study. Here, larger KAM values indicate a larger dislocation density or strain level. The metallic matrix of the 6Mn-d5 alloy consisted of a single $\gamma$-phase and no residual strain was detected, indicating that it was fully recrystallized. The other alloys used in this study were also confirmed to be fully recrystallized.

\section{B. Mechanical Properties of Recrystallized Alloys}

The mechanical properties and nominal stress-strain curves of the recrystallized $6 \mathrm{Mn}$ and Base alloys are shown in Figures 4 and 5, respectively. The values of the ultimate tensile strength, 0.2 pct proof stress, and plastic elongation of these alloys are summarized in Table III. The 6Mn-d20 alloy (recrystallization condition: $1523 \mathrm{~K}$, 150 seconds), whose grain size is acceptable for balloon-expandable stents, showed an ultimate tensile strength of $1131 \mathrm{MPa}, 0.2$ pct proof stress of 535 $\mathrm{MPa}$, and a plastic elongation of 66 pet.

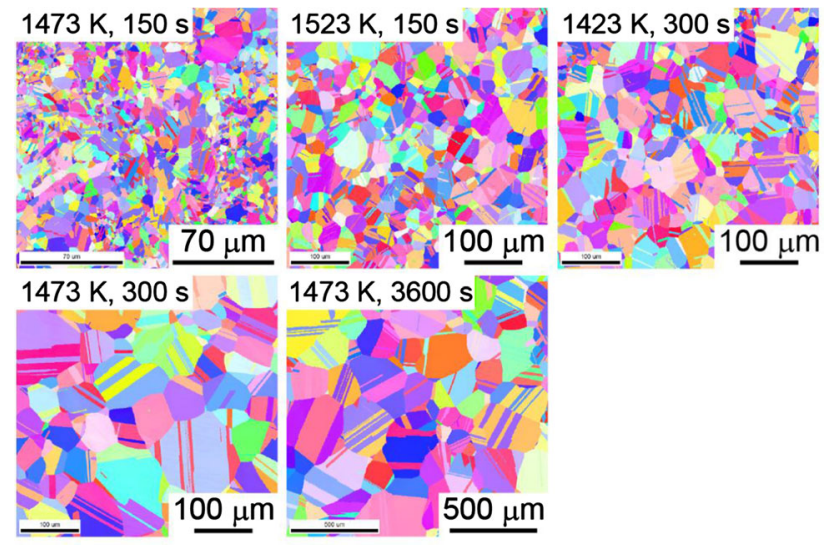

(a)
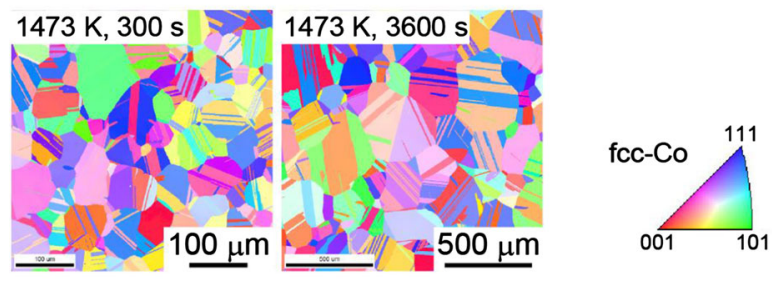

(b)

Fig. 2-EBSD IPF maps of $(a) 6 \mathrm{Mn}$ and $(b)$ Base alloys recrystallized at 1423 to $1523 \mathrm{~K}$ for 150 to $600 \mathrm{~s}$ with increasing grain size. 
Table II. Recrystallization Condition, Grain Size, and Abbreviation of 6Mn and Base Alloys

\begin{tabular}{lccc}
\hline & Recrystallization Condition & Grain Size, $d(\mu \mathrm{m})$ & Abbreviation \\
\hline $6 \mathrm{Mn}$ & $1473 \mathrm{~K}, 150 \mathrm{~s}$ & 5.4 & $6 \mathrm{Mn}-\mathrm{d} 5$ \\
& $1523 \mathrm{~K}, 150 \mathrm{~s}$ & 20.0 & $6 \mathrm{Mn}-\mathrm{d} 20$ \\
& $1423 \mathrm{~K}, 300 \mathrm{~s}$ & 21.7 & $6 \mathrm{Mn}-\mathrm{d} 22$ \\
& $1473 \mathrm{~K}, 300 \mathrm{~s}$ & 40.8 & $6 \mathrm{Mn}-\mathrm{d} 41$ \\
& $1473 \mathrm{~K}, 3600 \mathrm{~s}$ & 138.9 & $6 \mathrm{Mn}-\mathrm{d} 139$ \\
Base & $1473 \mathrm{~K}, 100 \mathrm{~s}$ & 6.0 & Base-d6 \\
& $1473 \mathrm{~K}, 300 \mathrm{~s}$ & 40.4 & Base-d40 \\
& $1473 \mathrm{~K}, 3600 \mathrm{~s}$ & 147.1 & Base-d147 \\
\hline
\end{tabular}

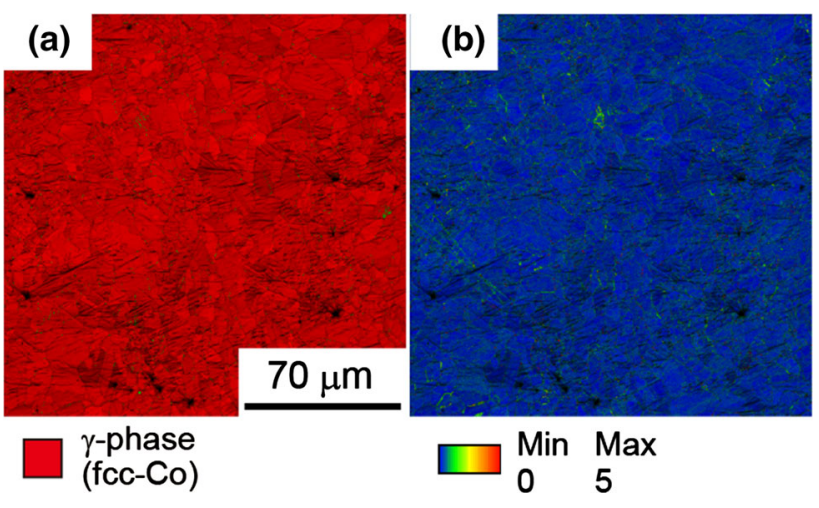

Fig. 3-EBSD (a) phase and (b) KAM maps of 6Mn-d5 alloys.

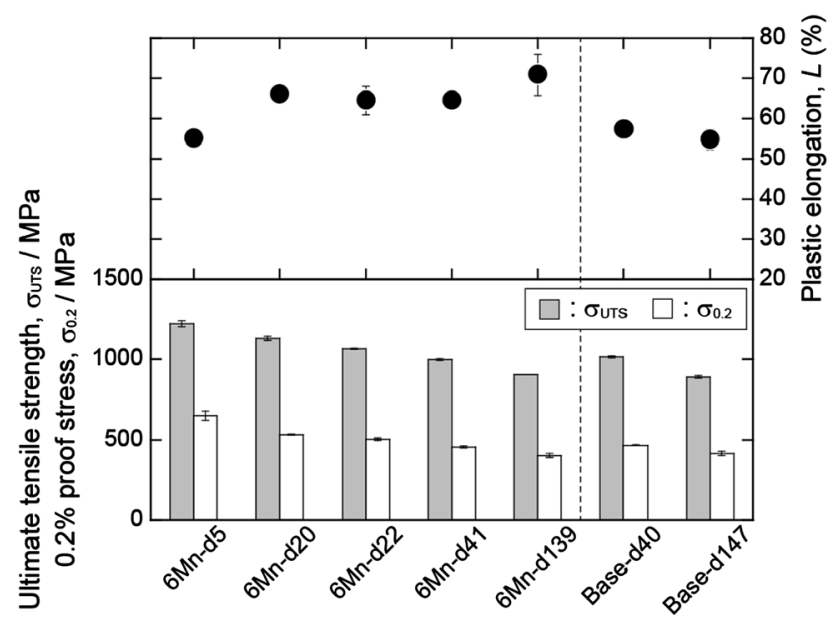

Fig. 4-Ultimate tensile strength, 0.2 pct proof stress, and plastic elongation of the recrystallized $6 \mathrm{Mn}$ and Base alloys.

Comparing 6Mn-d41 and Base-d40 alloys or 6Mn-d139 and Base-d147 alloys, which have similar grain sizes, the ultimate tensile strengths of the $6 \mathrm{Mn}$ and Base alloys are relatively close. However, the plastic elongations of the Base-d40 and Base-d147 alloys were 57 and 55 pct, respectively, and those of the $6 \mathrm{Mn}-\mathrm{d} 41$ and $6 \mathrm{Mn}-\mathrm{d} 139$ alloys were 65 and $71 \mathrm{pct}$, respectively.

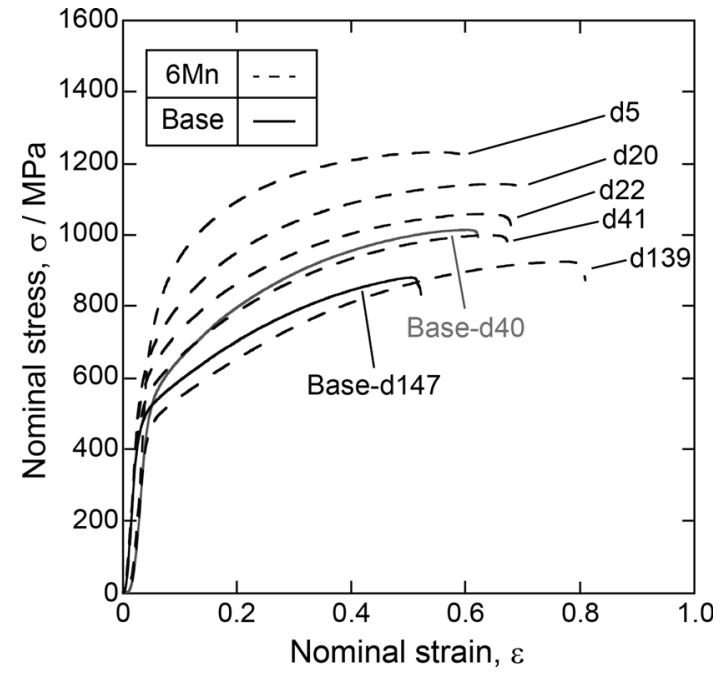

Fig. 5-Nominal stress-strain curves of the recrystallized $6 \mathrm{Mn}$ and Base alloys.

Table III. Ultimate Tensile Strength $\left(\sigma_{\mathrm{UTS}}\right), 0.2$ Pct

Proof Stress $\left(\sigma_{0.2}\right)$, and Plastic Elongation $(L)$ of Recrystallized 6Mn and Base Alloys

\begin{tabular}{lccc}
\hline & $\sigma_{\text {UTS }}(\mathrm{MPa})$ & $\sigma_{0.2}(\mathrm{MPa})$ & $L(\mathrm{Pct})$ \\
\hline 6Mn-d5 & 1222 & 654 & 55 \\
6Mn-d20 & 1131 & 535 & 66 \\
6Mn-d22 & 1065 & 505 & 65 \\
6Mn-d41 & 997 & 458 & 65 \\
6Mn-d139 & 906 & 405 & 71 \\
Base-d40 & 1015 & 468 & 57 \\
Base-d147 & 889 & 418 & 55 \\
\hline
\end{tabular}

These results indicate the higher ductility of the $6 \mathrm{Mn}$ alloys compared to the Base alloys. Moreover, the $6 \mathrm{Mn}$ alloys exhibited lower yield stress than the Base alloys. Hence, high ductility and low yield stress were achieved in Mn-added alloys while maintaining high strength.

\section{Corrosion Properties}

The corrosion resistance of the ST alloy (grain size: $147 \mu \mathrm{m}, 6 \mathrm{Mn}-\mathrm{d} 147$ (ST)) and recrystallized alloy (grain size: $20 \mu \mathrm{m}, 6 \mathrm{Mn}-\mathrm{d} 20$ ) were evaluated; they exhibited good mechanical properties. Figure 6 shows the anodic 


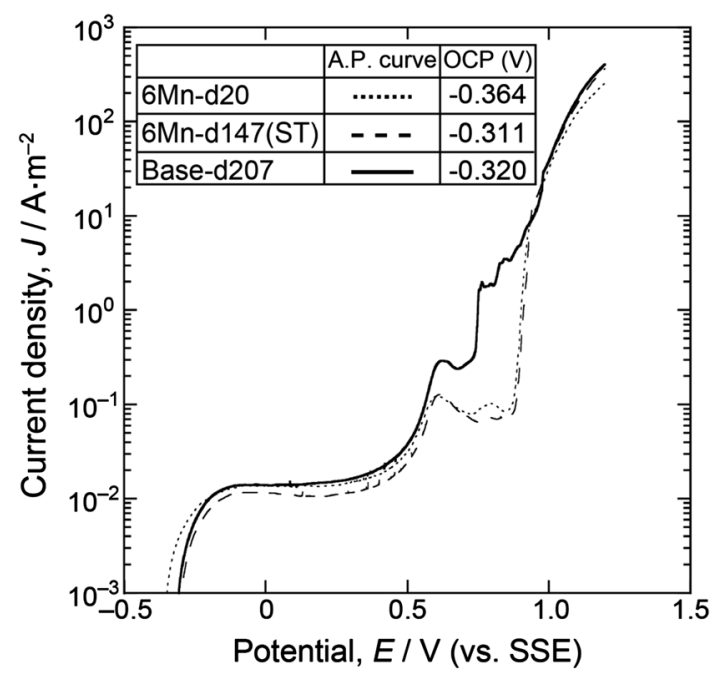

Fig. 6-Anodic polarization curves and open circuit potentials recorded for $6 \mathrm{Mn}-\mathrm{d} 20$, d147 (ST), and Base-d207 alloys.

polarization curves of the $6 \mathrm{Mn}-\mathrm{d} 147$ (ST), 6Mn-d20, and Base-d207 alloys in Hanks' balanced salt solution. The Base alloy without any thermomechanical treatment, which has a grain size of $207 \mu \mathrm{m}$ and is referred to as Base-d207, was used for comparison purposes. The OCP were approximately equal for all the alloys. Primary passive regions with constant current density in the range of approximately 0.3 to $0.4 \mathrm{~V}$ were confirmed in all the alloys. At potentials above $0.4 \mathrm{~V}$, transpassive regions were detected and the current density increased. Secondary passive regions were also detected at approximately 0.6 to $0.8 \mathrm{~V}$. Hence, it is evident that $6 \mathrm{Mn}-\mathrm{d} 20$ and $6 \mathrm{Mn}-\mathrm{d} 147$ (ST) alloys exhibit good corrosion resistance similar to Base alloys.

\section{DISCUSSIONS}

\section{A. Effect of Mn Addition on Yield Stress}

The yield stress $\left(0.2\right.$ pct proof stress, $\left.\sigma_{0.2}\right)$ of polycrystalline metals is expressed by the well-known Hall-Petch relationship as a function of the average grain size $(d)$, as shown in Eq. [1]..$^{[32,33]}$

$$
\sigma_{0.2}=\sigma_{0}+\frac{k_{\mathrm{HP}}}{\sqrt{d}}
$$

where $\sigma_{0}$ is the friction stress and $k_{\mathrm{HP}}$ is the Hall-Petch coefficient. Figure 7 shows the graph of 0.2 pct proof stress of recrystallized $6 \mathrm{Mn}$ and Base alloys plotted against $d^{-1 / 2}$. The regression lines calculated from each plot set using the least squares method are shown in the figure. Note that the regression line of the Base alloy was calculated using the data of recrystallized ASTM F90 CCWN alloys reported by Ueki et al. ${ }^{[17]}$ and those of the Base-d40 and Base-d147 alloys reported in this study. For both alloys, the 0.2 pct proof stress was linearly related to $d^{-1 / 2}$, indicating that the Hall-Petch relationship in Eq. [1] is valid. Based on the regression lines shown in Figure 7, the yield stress of 6Mn alloys is lower

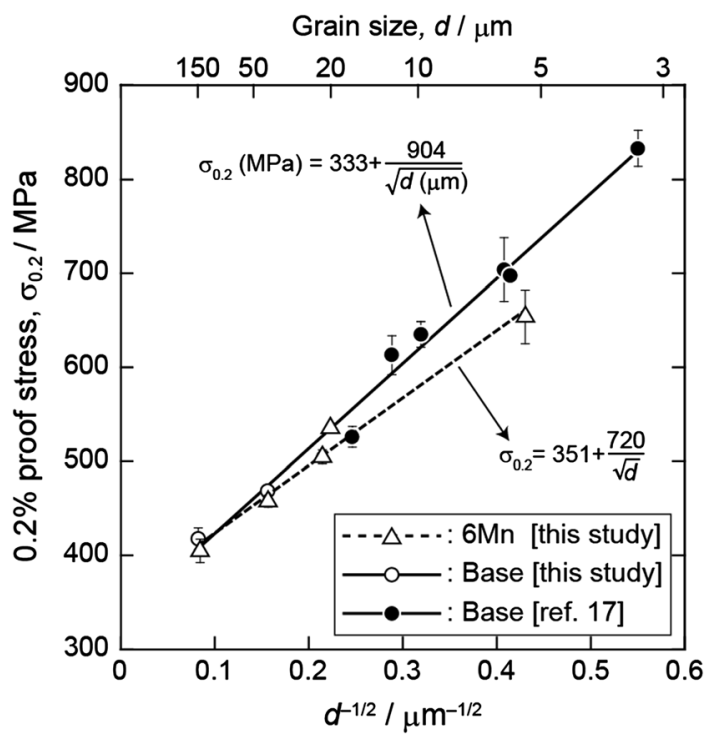

Fig. $7-0.2$ pct proof stress-grain size relationship of recrystallized $6 \mathrm{Mn}$ and Base alloys (data in Ref. [17] are included).

than that of the Base alloys; thus, the yield stress decreased with the addition of $\mathrm{Mn}$. Therefore, Mn-added CCWN alloys are suitable for balloon-expandable stents. The reason for the decrease in the yield stress with $\mathrm{Mn}$ addition is discussed below.

As aforementioned, $\mathrm{Mn}$, as a $\gamma$ stabilizing element in Co-based alloys, is known to increase SFE. ${ }^{[29,30]}$ The $\mathrm{SFE}$ of $\mathrm{Co}-x \mathrm{Mn}(x=0-10$ mass pet) binary system at $298 \mathrm{~K}$ was calculated using the thermodynamic parameters summarized in Table IV. The formulation to calculate SFE is shown in Eq. [2]. ${ }^{[34]}$

$$
\gamma_{\mathrm{sf}}=2 \rho \Delta G^{\gamma \rightarrow \varepsilon}+2 \sigma^{\gamma / \varepsilon}
$$

where $\gamma_{\mathrm{sf}}$ is the SFE $\left(\mathrm{mJ} \mathrm{m}^{-2}\right), \rho$ is the atomic density of the (111) plane per mole, $\Delta G^{\gamma \rightarrow \varepsilon}$ is the Gibbs free energy change of the $\gamma$ to $\varepsilon$ phase transformation, and $\sigma^{\gamma / \varepsilon}$ is the interfacial energy per unit area of the phase interface $\left(7.5 \mathrm{~mJ} \mathrm{~m}^{-2}\right.$ in Co-based alloys $\left.{ }^{[30]}\right)$. Based on the regular solution model, $\Delta G^{\gamma \rightarrow \varepsilon}$ is the sum of the change in the Gibbs free energy of each element $\left(\Delta G_{i}^{\gamma \rightarrow \varepsilon}\right)$, the excess free energy $\left(\Omega_{i j}^{\gamma \rightarrow \varepsilon}\right)$, and magnetic contribution to the Gibbs-free energy $\left(\Delta G_{\mathrm{mg}}^{\gamma \rightarrow \varepsilon}\right)$. In the Co-Mn binary system, the magnetic contribution to the Gibbs-free energy can be ignored $\left(\Delta G_{\mathrm{mg}}^{\gamma \rightarrow \varepsilon}=0\right)$. The calculation result of SFE is shown in Figure 8. Since the 6Mn alloys contain 50 mass pet of $\mathrm{Co}$ and 6 mass pet of $\mathrm{Mn}$, the ratio of the $\mathrm{Mn}$ content to the Co content is approximately 11 pct. Therefore, it was considered that the SFE increased by approximately $6 \mathrm{~mJ} \mathrm{~m} \mathrm{~m}^{-2}$ by adding 6 mass pct of Mn to the CCWN alloy. Here, we focused on analyzing the dislocation motion in alloys with different SFE values.

Ueki et al.$^{[15]}$ reported the existence of stacking faults in ASTM F90 CCWN alloys with a grain size of approximately $80 \mu \mathrm{m}$. Stacking faults can be obstacles to dislocation motion depending on their states. In $\mathrm{Co}-\mathrm{Cr}-\mathrm{Mo}-\mathrm{C}$ alloys, Rajan and Sande ${ }^{[37]}$ observed that 
Table IV. Thermodynamic Parameters of the Co-Mn Binary System Used in This Study

\begin{tabular}{llc}
\hline & \multicolumn{1}{c}{ Thermodynamic } \\
Parameters & \multicolumn{1}{c}{ Function $\left(\mathrm{J} \mathrm{mol}^{-1}\right)$} & References \\
\hline$\Delta G_{\mathrm{Co}}^{\gamma \rightarrow \varepsilon}$ & $-427.59+0.615 \mathrm{~T}$ & 35 \\
$\Delta G_{\mathrm{Mn}}^{\gamma \rightarrow \varepsilon}$ & $-1000+1.123 \mathrm{~T}$ & 35 \\
$\Omega_{\mathrm{CoMn}}^{\gamma \rightarrow \varepsilon}$ & $2756-1657\left(X_{\mathrm{Co}}-X_{\mathrm{Mn}}\right)$ & 36 \\
\hline
\end{tabular}

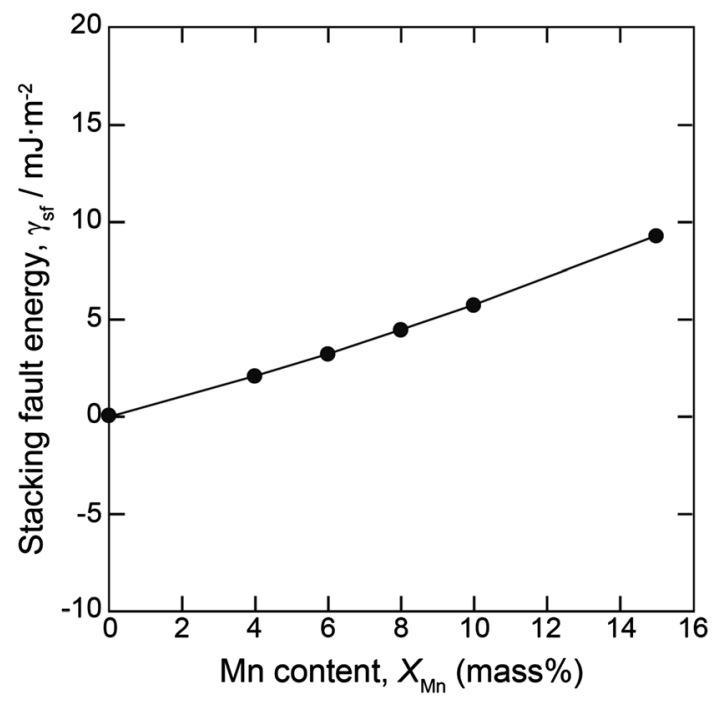

Fig. 8-Calculated stacking fault energy in the Co- $x \mathrm{Mn}$ binary system.
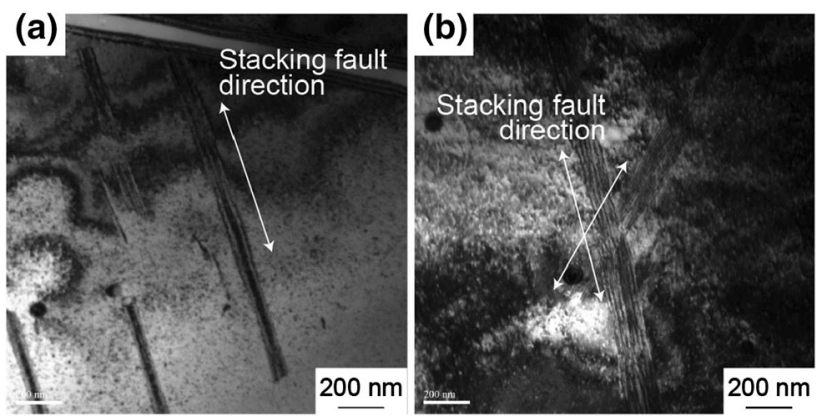

Fig. 9-TEM-BF images of stacking faults observed in (a) 6Mn-d5 and (b) Base-d6 alloys.

dislocations piled up at the intersections of stacking faults and indicated that the stacking faults themselves did not act as obstacles to dislocation motion, whereas intersecting stacking faults could be a major obstacle. Yamanaka et al. ${ }^{[38]}$ reported improved strengthening of Co-28Cr-6Mo (mass pet) alloys by introducing intersecting stacking faults using dynamic recrystallization. Zhu and Chen ${ }^{[24]}$ suggested that the existence of intersecting stacking faults formed during hot forging contributes to the strengthening of ASTM F90 CCWN alloys. Therefore, in this study, it is considered that stacking faults exist and may affect the yield stress in recrystallized 6Mn and Base alloys. Thus, we observed the microstructure of the recrystallized alloys in detail. TEM bright field (BF) images of $6 \mathrm{Mn}-\mathrm{d} 5$ and the Base alloy recrystallized at $1473 \mathrm{~K}$ for 100 seconds (grain size $6 \mu \mathrm{m}$, Base-d6) are shown in Figure 9. Intersecting stacking faults were observed in the Base-d6 alloy, unlike the $6 \mathrm{Mn}-\mathrm{d} 5$ alloy, which had stacking faults only in a single direction. This was because the Base alloy had a relatively low SFE and was more likely to cause intersections of stacking faults, whereas the $6 \mathrm{Mn}$ alloy had a high SFE, hindering the intersection of the stacking faults, which is known to inhibit dislocation motion. Thus, $\mathrm{Mn}$ addition is a promising approach for reducing yield stress of CCWN alloys.

In the coarse grain structure, a reduction in the yield stress by the addition of 6 mass pet Mn to CCWN alloy was not observed. On the other hand, in the 8 mass pet $\mathrm{Mn}$-added alloy, ${ }^{[26]}$ the yield stress was lower than that of the Base alloy even in the coarse grain structure. Lee et al. reported that grain coarsening reduces apparent SFE and facilitates the formation of stacking faults. ${ }^{[39]}$ In the coarse grain structure, the amount of decrease in the apparent SFE by grain coarsening was possibly larger than the amount of increase in the SFE by the addition of 6 mass pct Mn. Thus, the decrease in yield stress by the addition of 6 mass pet Mn to CCWN alloy with a coarse grain structure was not significant.

\section{B. Effect of Mn Addition on Ductility}

Figure 10 shows the EBSD IPF and phase maps of the fractured specimens after tensile tests for the alloys with grain sizes of $\sim 6 \mu \mathrm{m}(6 \mathrm{Mn}-\mathrm{d} 5$ and Base-d6), $\sim 40$ $\mu \mathrm{m}$ (6Mn-d41 and Base-d40), and $140 \mu \mathrm{m}$ (6Mn-d139 and Base-d147). Strain-induced martensitic transformation (SIMT) occurred around the grain boundaries and twin boundaries, regardless of the alloy composition or grain size. In ASTM F90 CCWN and Co-28Cr-6Mo (mass pct) alloys, it was experimentally determined that the SIMT $\varepsilon$-phase was formed at either grain boundaries or $\Sigma$ 3-annealing twin boundaries. ${ }^{[15,17,25,40]}$ The SIMT $\varepsilon$-phase was formed at similar sites in the $6 \mathrm{Mn}$ alloys in this study.

From the phase map shown in Figure 10, the $\varepsilon$-phase fractions $\left(f_{\varepsilon}\right)$ of each fractured specimen can be evaluated. Figure 11 shows the relationship between the $\varepsilon$-phase fraction and true strain at the fracture for each fractured specimen. Despite the grain size, the true strain at the fracture in 6Mn alloys with a high SFE was larger than that in the Base alloys. Moreover, the $\varepsilon$-phase fractions at the fracture for each grain size were approximately equal and independent of the SFE.

The microstructural evolution during plastic deformation was also investigated for the $6 \mathrm{Mn}-\mathrm{d} 139$ and Base-d147 alloys, which showed a significant difference in ductility. Figure 12 shows the EBSD IPF, KAM, and phase maps of the specimens with no true strain before the tensile test, with true strain levels of $0.15,0.4$, and after the fracture in tensile testing. The effect of true strain on the $\varepsilon$-phase fraction of the $6 \mathrm{Mn}-\mathrm{d} 139$ and Base-d147 alloys is shown in Figure 13. At least three phase maps were used to estimate the $\varepsilon$-phase fraction. 


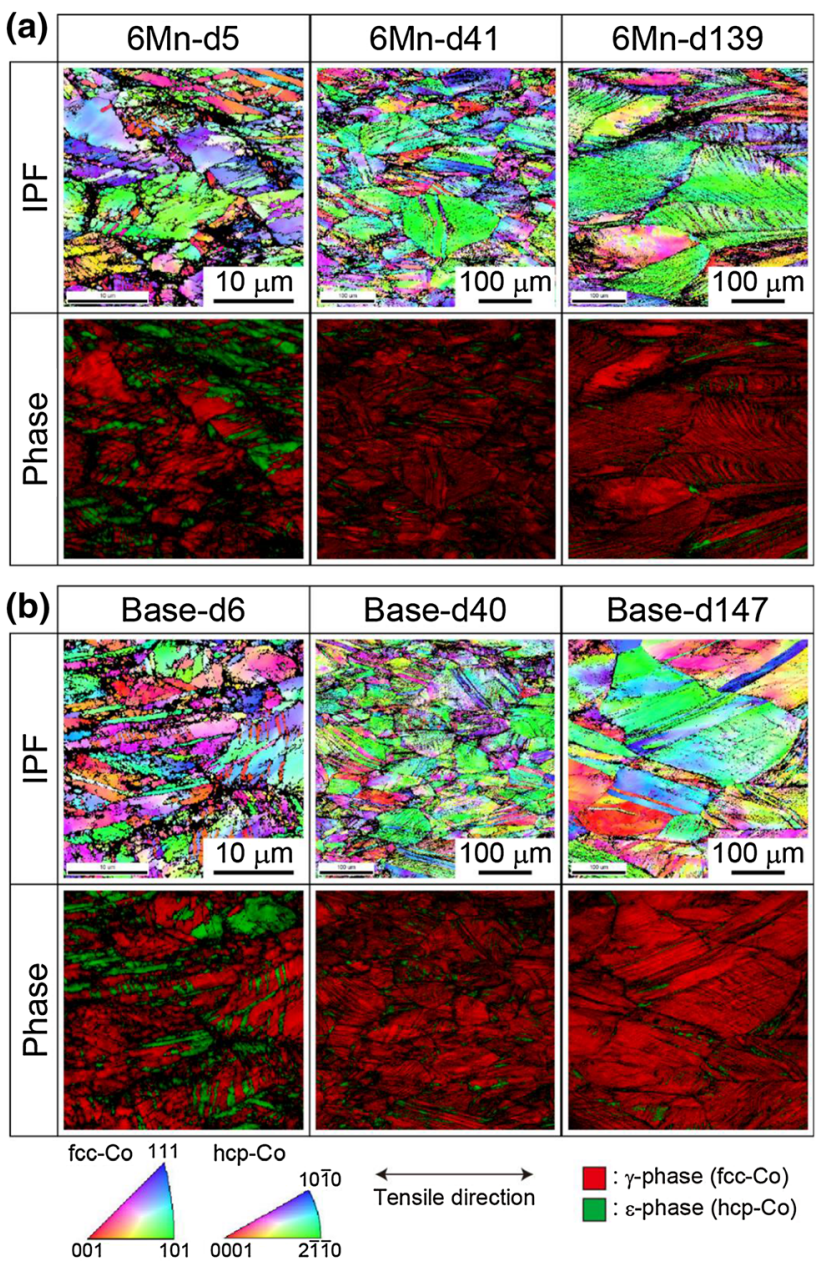

Fig. 10-EBSD IPF and phase maps of the fractured specimens after tensile test. (a) 6Mn-d5, 6Mn-d41, and 6Mn-d139 and (b) Base-d6, Base-d40, and Base-d147 alloys.

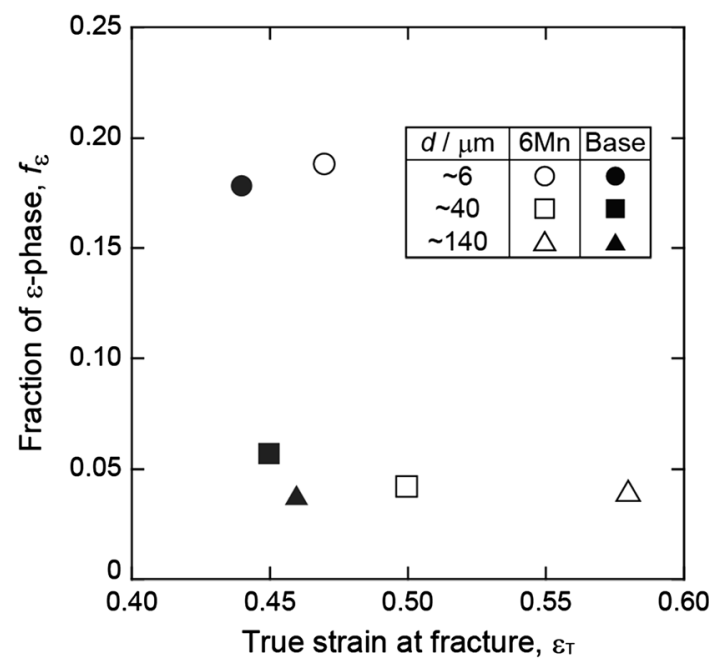

Fig. 11-Relationship between $\varepsilon$-phase fraction and the true strain of the fractured $6 \mathrm{Mn}$ and Base alloys.

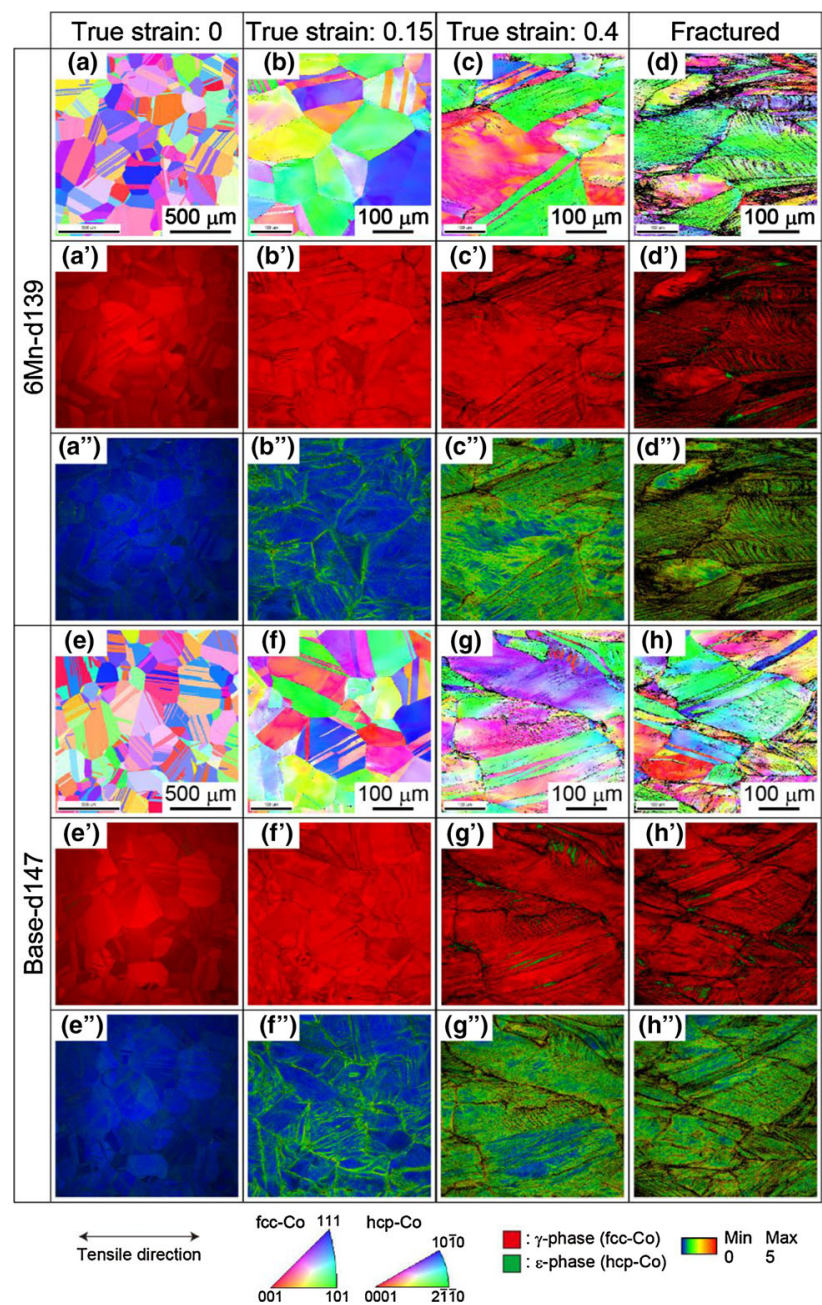

Fig. 12-EBSD $(a)$ through $(d),(e)$ through $(h)$ IPF, $\left(a^{\prime}\right)$ through $\left(d^{\prime}\right),\left(e^{\prime}\right)$ through $\left(h^{\prime}\right)$ phase, and $\left(a^{\prime \prime}\right)$ through $\left(d^{\prime \prime}\right),\left(e^{\prime \prime}\right)$ through $\left(h^{\prime \prime}\right)$ KAM maps of the strained 6Mn-d139 and Base-d147alloys.

In the early stage of deformation, up to a true strain level of 0.15 , both the $6 \mathrm{Mn}-\mathrm{d} 139$ and Base-d147 alloys consisted of a single $\gamma$-phase. As the KAM maps in Figure 12 show, the strain levels in both alloys increase at grain boundaries and twin boundaries, and dislocations accumulate at these sites. At this stage, only dislocation glide occurs instead of SIMT.

In the middle stage, at a true strain of $0.4, \varepsilon$-phase was formed through SIMT in both 6Mn and Base alloys. The $\varepsilon$-phase fraction of the $6 \mathrm{Mn}$ alloy was lower than that of the Base alloy, as shown in Figure 13. Rémy and Pineau ${ }^{[41]}$ reported that both SIMT and deformation twinning occurred in Co-based alloys when the SFE values were 15 to $20 \mathrm{~mJ} \mathrm{~m}^{-2}$, and the dominant modes were deformation twinning and dislocation slip when the SFE values were 20 to $30 \mathrm{~mJ} \mathrm{~m} \mathrm{~m}^{-2}$ and greater than $50 \mathrm{~mJ} \mathrm{~m}^{-2}$, respectively. This indicates that SIMT or deformation twinning is suppressed with increasing SFE. In our previous study, the SFE of the Base alloy was calculated using Thermo-Calc (thermodynamic 


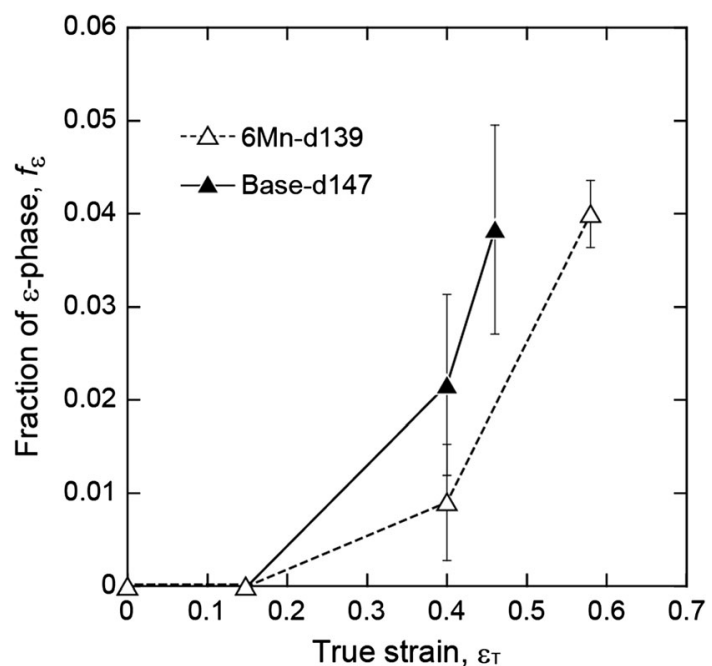

Fig. 13-Effect of true strain on $\varepsilon$-phase fraction of $6 \mathrm{Mn}$-d139 and Base-d147 alloys.

calculation software, database: TCFE9) and was estimated as approximately $25 \mathrm{~mJ} \mathrm{~m}^{-2}$ at $300 \mathrm{~K} .^{[17]}$ Considering the report by Rémy and Pineau, ${ }^{[41]}$ SIMT should not occur and only deformation twinning should occur in the Base alloy. However, in the Base alloys to which a strain of 30 pct or more was applied, the formation of $\varepsilon$-phase by SIMT was observed, ${ }^{17]}$ i.e., in the Co-based alloys, both SIMT and deformation twinning are considered to occur even when the SFE of the alloy is approximately $25 \mathrm{~mJ} \mathrm{~m}^{-2}$.

From our previous study ${ }^{[17]}$ and calculation results of SFE in the Co- $x$ Mn binary system shown in Figure 8, the SFE of $6 \mathrm{Mn}$ alloys was expected to be approximately $31 \mathrm{~mJ} \mathrm{~m}^{-2}$. Therefore, deformation twinning may occur preferentially when $6 \mathrm{Mn}$ alloys are plastically deformed at room temperature. From these results, in this study, SIMT could be suppressed in the middle stage of deformation owing to the increase in SFE with Mn addition.

In the fractured specimens at the last stage, the $\varepsilon$-phase fractions at the fracture were approximately the same despite the SFE, and the true strain at the fracture was higher in $6 \mathrm{Mn}$ alloy than in the Base alloy, as aforementioned. These results suggest that the onset of SIMT was delayed with increasing SFE. Therefore, it was noted that the $6 \mathrm{Mn}$ alloy showed higher ductility than the Base alloy.

\section{Effect of Mn Addition on Corrosion Properties}

Ha et al. ${ }^{[42]}$ reported that in $\mathrm{Fe}-23 \mathrm{Cr}-x \mathrm{Mn}(x=0,3$, 6, 8 mass pct) alloys without non-metallic inclusions, such as $\mathrm{MnS}$, the stability of passive films decreased owing to a decrease in the pitting potential with the addition of $\mathrm{Mn}$, indicating that $\mathrm{Mn}$ has a negative effect on the corrosion resistance of the alloys. However, in this study, there is no significant difference in OCP and passive current density between the $6 \mathrm{Mn}$ alloy and the Base alloy. The 6Mn alloys contain 19 mass pet of $\mathrm{Cr}$, which is within the ASTM F90 standard composition range. $\mathrm{Cr}$ promotes passivation of the alloy surface, and the 10 mass pet $\mathrm{Ni}$ provides other beneficial corrosion resistance effects. ${ }^{[43]}$ Furthermore, they contained 15 mass pct of $\mathrm{W}$, which increased the pitting resistance. These elements $(\mathrm{Cr}, \mathrm{Ni}$, and $\mathrm{W})$ may have reduced the negative effects of $\mathrm{Mn}$ addition to the Co alloys. Wang et $a{ }^{[44]}$ have developed a $\mathrm{Co}-20 \mathrm{Cr}-12 \mathrm{Fe}-18 \mathrm{Mn}-$ $2 \mathrm{Mo}-4 \mathrm{~W}-0.4 \mathrm{~N}$ alloy (mass pct) as a Ni-free $\mathrm{Co}-\mathrm{Cr}$ alloy for intravascular stents. They reported that even alloys containing 18 mass pct of $\mathrm{Mn}$, which are higher than that in the $6 \mathrm{Mn}$ alloys, have the same level of corrosion resistance as ASTM F90 CCWN alloy. Therefore, it was considered that the addition of $\mathrm{Mn}$ up to 6 mass pet would not significantly affect the primary passivation film formation behavior of CCWN alloys in body fluids.

In the secondary passivation region, the $6 \mathrm{Mn}$ alloys showed lower current densities than the Base alloys. The main factor of secondary passivation in the CCWN alloys is considered to be the formation of $\mathrm{CoO}$ and/or $\mathrm{Co}_{2} \mathrm{O}_{3} \cdot{ }^{[45]}$ It was presumed that $\mathrm{Mn}_{2} \mathrm{O}_{3}$ was formed by adding $\mathrm{Mn}$ to the CCWN alloy, which contributed to the secondary passivation along with cobalt oxides. ${ }^{[46]}$ Therefore, the current density of the 6Mn alloys in the secondary passivation region was lower than that of the Base alloy.

The effects of CCWN alloy Mn content on pitting and crevice corrosion behavior have not been analyzed in this study, and thus, further investigation is required.

\section{CONCLUSIONS}

In this study, we developed a $\mathrm{Co}-\mathrm{Cr}-\mathrm{W}-\mathrm{Ni}-\mathrm{Mn}$ alloy by adding 6 mass pet of Mn to the ASTM F90 CCWN alloy for use as balloon-expandable stents and subjected it to thermomechanical treatment. The effects of adding $\mathrm{Mn}$ on the microstructure, mechanical properties, and corrosion properties of the alloys were investigated. The following conclusions were drawn:

1. The yield stress of the recrystallized alloys decreased with the addition of Mn. This might be owing to the suppression of intersecting stacking faults caused by increasing the SFE with the addition of $\mathrm{Mn}$.

2. The 6Mn alloys showed higher ductility than the ASTM F90 CCWN alloys because of the suppression of SIMT from the $\gamma$-phase to $\varepsilon$-phase by increasing the SFE.

3. The 6Mn alloys showed good corrosion resistance similar to ASTM F90 CCWN alloy.

4. The $6 \mathrm{Mn}$ alloy with a grain size of $\sim 20 \mu \mathrm{m}$ (recrystallization condition: $1523 \mathrm{~K}, 150$ seconds) exhibited an ultimate tensile strength of $1131 \mathrm{MPa}, 0.2$ pct proof stress of $535 \mathrm{MPa}$, and a plastic elongation of 66 pct. This alloy is a candidate for a balloon-expandable stent material because of its higher ductility and lower yield stress while maintaining high strength compared to ASTM F90 CCWN alloys. 


\section{ACKNOWLEDGMENTS}

This study was financially supported by the Japan Society for the Promotion of Science KAKENHI [Grant Numbers JP 18H05254 and 19K23580]. We thank Dr. K. Kobayashi of Tohoku University for TEM analysis.

\section{OPEN ACCESS}

This article is licensed under a Creative Commons Attribution 4.0 International License, which permits use, sharing, adaptation, distribution and reproduction in any medium or format, as long as you give appropriate credit to the original author(s) and the source, provide a link to the Creative Commons licence, and indicate if changes were made. The images or other third party material in this article are included in the article's Creative Commons licence, unless indicated otherwise in a credit line to the material. If material is not included in the article's Creative Commons licence and your intended use is not permitted by statutory regulation or exceeds the permitted use, you will need to obtain permission directly from the copyright holder. To view a copy of this licence, visit http://creat ivecommons.org/licenses/by/4.0/.

\section{REFERENCES}

1. P. Poncin and J. Proft: Proc. Mater. Processes Med. Devices Conf., 2003, pp. 253-59.

2. J. Favre, Y. Koizumi, A. Chiba, D. Fabregue, and E. Maire: Metall. Mater. Trans. A, 2013, vol. 44A, pp. 2819-30.

3. F.R. Morral: J. Mater., 1966, vol. 1, pp. 384-412.

4. R.V. Marrey, R. Butgermeister, R.B. Grishaber, and R.O. Ritchie: Biomaterials, 2006, vol. 27, pp. 1988-2000.

5. P. Poncin, C. Millet, J. Chevy, and J.L. Proft: Proc. Mater. Processes Med. Devices Conf., 2004, pp. 279-83.

6. A. Khalilimeybodi, A.A. Khoei, and B. Sharif-Kashani: Cardiovasc. Eng. Technol., 2019, vol. 11, pp. 188-204.

7. J. Favre, D. Fabrègue, E. Maire, and A. Chiba: Philos. Mag., 2014, vol. 94, pp. 1992-2008.

8. V.A. Kumar, R.K. Gupta, S.V.S.N. Murty, and A.D. Prasad: $J$. Alloy. Compd., 2016, vol. 676, pp. 527-41.

9. R.K. Gupta, M.K. Karthikeyan, D.N. Bhalia, B.R. Ghosh, and P.P. Sinha: Met. Sci. Heat Treat., 2008, vol. 50, pp. 175-78

10. J. Teague, E. Cerreta, and M. Stout: Metall. Mater. Trans. A, 2004 , vol. 35A, pp. 2767-81.

11. N. Yukawa and K. Sato: Mater. Trans. JIM, 1968, vol. 9, pp. $680-86$.

12. M. Tanaka and H. Iizuka: Metall. Mater. Trans. A, 1992, vol. 23A, pp. 609-16.

13. T. Narushima, S. Mineta, Y. Kurihara, and K. Ueda: JOM, 2013, vol. 65 , pp. $489-504$.

14. H.M. Tawancy, V.R. Ishwar, and B.E. Lewis: J. Mater. Sci. Lett., 1986, vol. 5, pp. 337-41.
15. K. Ueki, K. Ueda, M. Nakai, T. Nakano, and T. Narushima: Metall. Mater. Trans. A, 2018, vol. 49A, pp. 2393-2404.

16. Z. Zhu, L. Meng, and L. Chen: Rare Met., 2020, vol. 39, pp. 241-49.

17. K. Ueki, S. Yanagihara, K. Ueda, M. Nakai, T. Nakano, and T. Narushima: Mater. Sci. Eng. A, 2019, vol. 766, art. no. 138400.

18. K. Ueki, K. Ueda, and T. Narushima: Metall. Mater. Trans. A, 2016, vol. 47A, pp. 2773-82.

19. C.L. Li, C.H. Park, S.W. Choi, S.W. Lee, J.K. Hong, and J.T. Yeom: Mater. Sci. Eng. A, 2018, vol. 732, pp. 70-77.

20. C.L. Li, J.M. Oh, J.T. Yeom, and C.H. Park: J. Alloys Compd., 2019, vol. 783, pp. 173-78.

21. C.L. Li, J.M. Oh, S.W. Choi, J.K. Hong, J.T. Yeom, X.M. Mei, Q. Mei, Z. Yu, and C.H. Park: Mater. Sci. Eng. A, 2020, vol. 785, art. no. 139388.

22. C.L. Li, S.W. Choi, J.M. Oh, J.K. Hong, J.T. Yeom, J.H. Kang, Q.S. Mei, and C.H. Park: Rare Met., 2021, vol. 40, pp. 20-30.

23. C.L. Li, J.M. Oh, S.W. Choi, X.M. Mei, J.K. Hong, J.T. Yeom, Q.S. Mei, Z.T. Yu, and C.H. Park: Rare Met., 2021, vol. 40, pp. 877-84.

24. Z. Zhu and L. Chen: Mater. Res. Express, 2019, vol. 6, art. no. 126511.

25. K. Ueki, M. Abe, K. Ueda, M. Nakai, T. Nakano, and T. Narushima: Mater. Sci. Eng. A, 2019, vol. 739, pp. 53-61.

26. K. Ueki, S. Yanagihara, K. Ueda, M. Nakai, T. Nakano, and T. Narushima: Mater. Trans., 2021, vol. 62, pp. 229-38.

27. S. Curtze and V.-T. Kuokkala: Acta Mater., 2010, vol. 58, pp. $5129-41$.

28. C.T. Sims, N.S. Stoloff, and W.C. Hagel: Superalloys II, Wiley, New York, NY, 1987, pp. 135-162.

29. T.L. Achmad, W. Fu, H. Chen, C. Zhang, and Z.G. Yang: Comput. Mater. Sci., 2016, vol. 121, pp. 86-96.

30. T.L. Achmad, W. Fu, H. Chen, C. Zhang, and Z.G. Yang: $J$. Alloys Compd., 2017, vol. 694, pp. 1265-79.

31. Alfirano, S. Mineta, S. Namba, T. Yoneda, K. Ueda, and T. Narushima: Metall. Mater. Trans. A, 2011, vol. 42A, pp. 1941-49.

32. E.O. Hall: Proc. Phys. Soc. B, 1951, vol. 64, pp. 747-53.

33. N.J. Petch: J. Iron Steel Inst., 1953, vol. 174, pp. 25-28.

34. G.B. Olson and M. Cohen: Metall. Trans. A, 1976, vol. 78A, pp. 1897-1904.

35. A.T. Dinsdale: Calphad, 1991, vol. 15, pp. 317-425.

36. W. Huang: Calphad, 1989, vol. 13, pp. 231-42.

37. K. Rajan and J.B.V. Sande: J. Mater. Sci., 1982, vol. 17, pp. 769-78.

38. K. Yamanaka, M. Mori, S. Sato, and A. Chiba: Sci. Rep., 2017, vol. 7, p. 10808

39. Y.K. Lee and C.S. Choi: Metall. Mater. Trans. A, 2000, vol. 31A, pp. $355-60$.

40. M. Mori, K. Yamanaka, and A. Chiba: J. Mech. Behav. Biomed. Mater., 2015, vol. 55, pp. 201-14.

41. L. Rémy and A. Pineau: Mater. Sci. Eng., 1976, vol. 26, pp. 123-32.

42. H.Y. Ha, M.H. Jang, and T.H. Lee: Electrochim. Acta, 2016, vol. 191, pp. 864-75.

43. T. Nishimura, H. Katayama, K. Noda, and T. Kodama: Corros. Sci., 2000, vol. 42, pp. 1611-21.

44. Q. Wang, Y. Ren, M.B. Shahzad, W. Zhang, X. Pan, S. Zhang, and D. Zhang: Mater. Sci. Eng. C, 2017, vol. 77, pp. 565-71.

45. A. Kocijan, I. Milošev, and B. Pihlar: J. Mater. Sci.-Mater. Med., 2004, vol. 15, pp. 643-50.

46. Y.S. Zhang, X.M. Zhu, and S.H. Zhong: Corros. Sci., 2004, vol. 46 , pp. $853-76$.

Publisher's Note Springer Nature remains neutral with regard to jurisdictional claims in published maps and institutional affiliations. 